\title{
Avaliação da educação superior no Brasil, aspectos históricos e legais
}

\author{
Evaluation of higher education in Brazil, historical and legal aspects
}

\author{
Juliana da Silva Dias ${ }^{1}$ - Universidade Tiradentes | Aracaju | SE | Brasil. Contato: \\ julianasilvadias7@gmail.com . https://orcid.org/0000-0003-4988-2692 \\ Cassius Gomes de Oliveira² - Universidade Tiradentes | Aracaju | SE | Brasil. Contato: \\ cassius.gomes@souunit.com.br. https://orcid.org/0000-0002-2035-2850
}

\begin{abstract}
Resumo: O artigo objetiva assinalar indícios históricos e legais no que tange a avaliação da Educação Superior no Brasil, evidenciando fatos que favoreceram a construção do processo de avaliação atualmente observado. Entende-se que estudar a história é fator preponderante, para se apreender o modelo avaliativo vigente e propor mudanças nestes mecanismos tão presentes no cotidiano das IES. A escolha por uma opção metodológica qualitativa, justifica-se pelo interesse na realização de análises profundas que ultrapassem o limite da superficialidade possibilitando uma compreensão mais completa dos fatos e variáveis que tangenciam o objeto investigado. O estudo revela que fragilidades se mantém ao logo do tempo, pois já no final da Primeira República, evidenciavam-se problemas, como a falta de estrutura universitária; revelando então a necessidade de se estabelecer políticas públicas capazes de melhor estruturar a Educação Superior no Brasil.
\end{abstract}

Palavras-chave: Educação superior. Avaliação. Qualidade.

\begin{abstract}
The article aims to point out historical and legal evidence regarding the evaluation of Higher Education in Brazil, evidencing facts that favored the construction of the evaluation process currently observed. It is understood that studying history is a preponderant factor, in order to apprehend the current evaluative model and propose changes in these mechanisms so present in the daily life of HEIs. The choice for a qualitative methodological option is justified by the interest in conducting deep analyzes that exceed the limit of superficiality, allowing a more complete understanding of the facts and variables that touch the investigated object. The study reveals that weaknesses remain to the time, since at the end of the First Republic, problems such as lack of university structure were evident; thus revealing the need to establish public policies capable of better structuring Higher Education in Brazil.
\end{abstract}

Keywords: Higher Education. Evaluation. Quality.

- Recebido em: 12 de julho de 2018 • Aprovado em: 12 de maio de 2020

DOI: http://dx.doi.org/10.1590/S1414-4077/S1414-40772020000200001

Este é um artigo publicado em acesso aberto sob uma licença Creative Commons https://creativecommons.org/licenses/by-nc/4.0/ 


\section{Introdução}

Estudar os aspectos históricos e legais relacionados a avaliação da Educação Superior, torna-se necessário, para melhor se apreender o modelo vigente bem como os mecanismos da avaliativos tão presentes no cotidiano das IES e dos seus cursos.

Os fatos aqui considerados têm como marco temporal inicial o ano de 1889. Uma vez que, o Brasil, não possuiu Universidades durante o período colonial, existiam inicialmente, escolas autônomas. Segundo Teixeira (1969), o sistema se expandiu muito lentamente e ao se proclamar a República, em 1889, não havia mais que 24 dessas escolas. Os relatos históricos evidenciam que com a Proclamação da República (1889) e a nova Constituição descentralizouse a Educação Superior, permitindo a criação de novas instituições, tanto a partir da iniciativa pública como privada.

Apesar da criação das citadas escolas, conforme se observa ao estudar a história aqui considerada, é importante registrar que não se verificou outra preocupação que não fosse a de formar profissionais necessários ao aparelhamento do Estado, como advogados, engenheiros e médicos. Concepção também observada nos dias atuais, uma Educação Superior que tem como foco a formação de profissionais, para atender o mercado de trabalho.

Uma característica tão presente na Educação Superior Brasileira deve ser, sim, levada em consideração nas avaliações externas de curso. Não apenas em relação a empregabilidade, mas também no que diz respeito a formação destes profissionais. Afinal espera-se que a Educação Superior ofertada seja capaz de formar profissionais aptos a atuarem em suas áreas. E caso não seja, espera-se que, de alguma forma, a avaliação externa de cursos de graduação possibilite mudanças que favoreçam a qualidade da educação ofertada e a formação de futuros profissionais. Vale destacar que, a avaliação externa de curso não contempla, necessariamente, insumos relacionados a empregabilidade, ou mesmo tem espaço para ouvir a opinião dos empregadores. Entende-se que estes aspectos deveriam ser considerados desde a autorização de um curso.

\section{Percurso metodológico}

Ao classificar esta pesquisa, considerando seu objetivo vale ressaltar Gil (2007) quando explica que com base nos objetivos, é possível classificar as investigações científicas em três grupos: exploratória, descritiva e explicativa. Assim, caracteriza-se tal pesquisa como exploratória, pois se preocupa em identificar os fatores que determinam ou que contribuem para 
a ocorrência dos fenômenos. A escolha de se enveredar por uma opção metodológica como a qualitativa, neste estudo, justifica-se pelo interesse na realização de análises mais profundas que ultrapassem o limite da superficialidade e que possibilitem uma compreensão mais completa dos fatos e variáveis que tangenciam o objeto aqui investigado, ou seja as avaliações da Educação Superior.

Este estudo teve como base metodológica a pesquisa documental, realizada com o seguinte objetivo: assinalar indícios históricos e legais relativos a avaliação da Educação Superior no Brasil, evidenciando fatos que favoreceram a construção do modelo avaliativo atualmente observado. Conforme esclarece, Fonseca (2002, p. 32):

\begin{abstract}
A pesquisa documental trilha os mesmos caminhos da pesquisa bibliográfica, não sendo fácil por vezes distingui-las. A pesquisa bibliográfica utiliza fontes constituídas por material já elaborado, constituído basicamente por livros e artigos científicos localizados em bibliotecas. A pesquisa documental recorre a fontes mais diversificadas e dispersas, sem tratamento analítico, tais como: tabelas estatísticas, jornais, revistas, relatórios, documentos oficiais, cartas, filmes, fotografias, pinturas, tapeçarias, relatórios de empresas, vídeos de programas de televisão, etc.
\end{abstract}

Desta forma, a pesquisa documental aqui realizada, foi pautada em documentos legais relacionados a Educação Superior Brasileira, como decretos, leis e portarias, e também em instrumentos de avaliação adotados nos processos de avaliação externa de curso de graduação no Brasil.

Para tanto, documentos foram identificados, decompostos e estudados, Appolinário (2009, p. 67), define documentos como sendo: "Qualquer suporte que contenha informação registrada, formando uma unidade, que possa servir para consulta, estudo ou prova". A pesquisa documental aqui ressaltada, muito contribuiu com o desenvolvimento deste estudo, uma vez que de acordo com Sánchez (2012, p. 167) “Os fenômenos educativos por sua natureza social se tornam também históricos, e, nesse sentido, é que se supõe que toda investigação em educação trabalhe necessariamente com a historicidade".

Enfatiza-se que, as etapas de identificação, decomposição e análise dos documentos favoreceu a produção e a (re)elaboração de conhecimentos, criando novas formas de se perceber e compreender o objeto estudado. Contudo, May (2004) afirma que os documentos não existem isoladamente, precisam ser situados em uma estrutura teórica para que o seu conteúdo seja entendido. Destarte, esta pesquisa considerou caracterizações, definições, aspectos legais e conjecturas educacionais como base teórica para a análise proposta.

De acordo com Oliveira (2007), a pesquisa documental, exige do pesquisador uma análise criteriosa, em geral baseada em conteúdo, visto que os documentos ainda não passaram Avaliação, Campinas; Sorocaba, SP, v. 25, n. 2, p. 238-256, jul. 2020 
por nenhum tratamento científico. De acordo com Appolinário (2009, p. 27), pode-se entender como sendo análise de conteúdo:

Conjunto de técnicas de investigação científicas utilizadas em ciências humanas, caracterizadas pela análise de dados linguísticos. [...]. Normalmente, nesse tipo de análise, os elementos fundamentais da comunicação são identificados, numerados e categorizados. Posteriormente as categorias encontradas são analisadas face a uma teoria específica.

Consequentemente, a análise de conteúdo foi o mecanismo utilizado para interpretar os documentos analisados. De acordo com Bardin (2009, p. 121), as diferentes fases da análise de conteúdo organizam-se em torno de três polos: "1. A pré análise; 2. A exploração do material; e, por fim, 3. O tratamento dos resultados: a inferência e a interpretação".

Chizzotti (2006), comenta que um texto contém sentidos e significados, que podem ser apreendidos pelo leitor que interpreta a mensagem nele contida por meio de técnicas metódicas. Logo, a mensagem pode ser apreendida, decompondo-se o conteúdo do documento em fragmentos mais simples, que revelem sutilezas contidas no texto. Os fragmentos podem ser palavras, termos ou frases significativas de uma mensagem, que poderão favorecer o entendimento dos fatos a partir do contexto em que estão postos.

\section{As reformas educacionais}

No decorrer do período, denominado pelos historiadores como Primeira República (1889-1930), o Governo Federal Brasileiro realizou múltiplas reformas no campo educacional. Os fatos que serão aqui apresentados possuem como eixo estruturante tais reformas, conforme apresentado a seguir:
a) Reforma Benjamin Constant (1890);
b) Reforma Epitácio Pessoa (1901);
c) Reforma Rivadávia Correa (1911);
d) Reforma Carlos Maximiliano (1915).

As informações organizadas no Quadro 1, sintetizam os aspectos históricos relacionados a este estudo considerando cada uma das reformas citadas anteriormente. 


\section{Quadro 1 - Reformas Educacionais - Indícios Históricos - correlacionados com os processos de avaliação e regulação vigentes no Brasil (Continua)}

\begin{tabular}{|c|c|c|c|c|}
\hline \multicolumn{2}{|c|}{$\begin{array}{l}\text { Reformas } \\
\text { Educacionais }\end{array}$} & \begin{tabular}{ccc} 
Considerações & relevantes para \\
o estudo, a partir das \\
Reformas & \multicolumn{2}{c}{ Educacionais }
\end{tabular} & $\begin{array}{l}\text { Documentos estudados, } \\
\text { em função das Reformas } \\
\text { Educacionais }\end{array}$ & $\begin{array}{l}\text { Indícios históricos correlacionados com os processos de avaliação e } \\
\text { regulação vigentes no Brasil }\end{array}$ \\
\hline 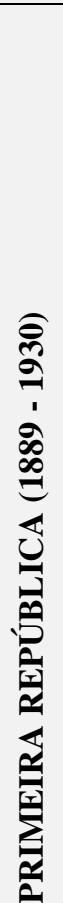 & $\begin{array}{l}\text { Reforma } \\
\text { Benjamin } \\
\text { Constant } \\
\text { 1890. }\end{array}$ & $\begin{array}{l}\text { Promoveu o alargamento dos canais } \\
\text { de acesso à Educação Superior. } \\
\text { Criou condições legais para que } \\
\text { escolas superiores mantidas por } \\
\text { particulares viessem a conceder } \\
\text { diplomas dotados do mesmo valor } \\
\text { dos expedidos pelas faculdades } \\
\text { federais }\end{array}$ & $\begin{array}{l}\text { Decreto } 1232-\mathrm{G}, \text { de } 2 \text { de janeiro } \\
\text { de } 1891 . \\
\text { Decreto } 1232-\mathrm{H} \text {, de } 2 \text { de janeiro } \\
\text { de } 1891 . \\
\text { Decreto } 1159 \text {, de } 3 \text { de } \\
\text { dezembro de } 1892 \text {. Neste } \\
\text { documento já se observa } \\
\text { claramente que desde então } \\
\text { uma série de condições } \\
\text { deveria ser observada junto a } \\
\text { Educação Superior, e a cada } \\
\text { ano um inspetor do Governo } \\
\text { visitava a instituição para } \\
\text { relatar as condições de } \\
\text { funcionamento, o que poderia } \\
\text { resultar no encerramento das } \\
\text { atividades ou no aval para a } \\
\text { continuidade. Muito } \\
\text { semelhante ao modelo que se } \\
\text { observa atualmente. Já se } \\
\text { previa: } \\
\text { Critérios para ingresso e } \\
\text { permanência da instituição e } \\
\text { dos cursos no sistema de } \\
\text { ensino; }\end{array}$ & $\begin{array}{l}\text { "Alargamento dos canais de acesso". Fato histórico, marcante e atual na Educação } \\
\text { Superior Brasileira. } \\
\text { O Decreto } 1232-G \text {, de } 1891 \text {, já previa a aprovação dos "programas de ensino das escolas } \\
\text { federais, e das que lhes fossem equiparadas". Neste sentido, cita-se que atualmente, as } \\
\text { matrizes curriculares dos cursos são anexadas aos processos de avaliação externa, logo } \\
\text { também passam por um processo de aprovação, realizado por meio dos órgãos } \\
\text { reguladores. Ainda considerando o Decreto } 1232-G \text {, de } 1891 \text {, o Conselho de Instrução } \\
\text { Superior deveria propor ao Governo Federal "regulamentos para a inspeção de tais } \\
\text { estabelecimentos", atualmente estes regulamentos estão materializados nos instrumentos } \\
\text { de avaliação, na legislação que dita regras a serem seguidas em atendimentos aos } \\
\text { processos regulatórios, a exemplo cita-se o Decreto n }{ }^{\circ} 5773 \text {, de } 9 \text { de maio de } 2006 \text {, } \\
\text { vigente até } 15 \text { de dezembro de } 2017 \text {, revogado pelo Decreto ñ } 9235 \text {, de } 15 / 12 / 2017 \text {, } \\
\text { ambos que dispunham sobre o exercício das funções de regulação, supervisão e avaliação } \\
\text { de IES e cursos superiores de graduação. }\end{array}$ \\
\hline
\end{tabular}




\section{Quadro 1 - Reformas Educacionais - Indícios Históricos - correlacionados com os processos de avaliação e regulação vigentes no Brasil (Continuação)}

\begin{tabular}{|c|c|c|c|c|}
\hline \multicolumn{2}{|c|}{$\begin{array}{l}\text { Reformas } \\
\text { Educacionais }\end{array}$} & \multirow[t]{2}{*}{$\begin{array}{ccr}\text { Considerações relevantes para } \\
\text { o estudo, a partir das } \\
\text { Reformas } & \text { Educacionais } \\
\text { estudadas } & \end{array}$} & \multirow{2}{*}{ 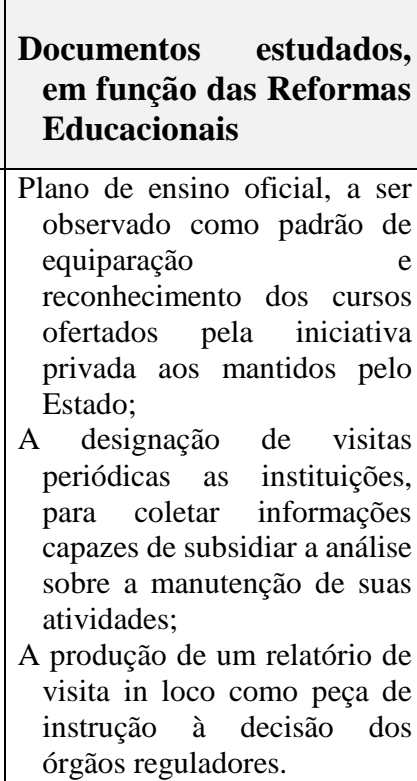 } & \multirow{2}{*}{$\begin{array}{l}\text { Indícios históricos correlacionados com os processos de avaliação e } \\
\text { regulação vigentes no Brasil } \\
\text { Decreto 1232-H, de 1891, aprovou o regulamento das Instituições de Ensino Jurídico } \\
\text { existentes no Brasil, e permitiu aos particulares a fundação de escolas de Direito, os } \\
\text { diplomas por elas expedidos teriam o mesmo valor daqueles expedidos pelas duas } \\
\text { faculdades oficiais, a de São Paulo e a de Olinda, desde que incluíssem nos currículos } \\
\text { as mesmas disciplinas presentes no currículo dos oficiais. Atualmente os processos } \\
\text { avaliativos, que atendem a todos os cursos, e não apenas aos cursos de Direito, não } \\
\text { explicitam a necessidade de se incluir disciplinas nos currículos, mas exigem o } \\
\text { atendimento ao previsto nas Diretrizes Curriculares Nacionais (DCN's) e no Catálogo } \\
\text { Nacional dos Cursos Superiores de Tecnologia. Vale destacar que ambos, são fontes } \\
\text { de consulta previstas no instrumento de avaliação de cursos de graduação. Quanto a } \\
\text { "inspeção periódica" hoje acontecem na forma de avaliações periódicas in loco. } \\
\text { O Decreto 1159, de } 1892 \text { já destacava a atuação da iniciativa privada bem como a } \\
\text { necessidade de inspeções periódicas na Educação Superior, em seu Art. 310, já } \\
\text { determinava que: "É permitido a qualquer indivíduo ou associação de particulares a } \\
\text { fundação de cursos ou estabelecimentos, onde se ensinem as matérias que constituem } \\
\text { o programa de qualquer curso ou estabelecimento official de ensino superior, salvo a } \\
\text { inspeção necessária para garantir as condições de moralidade e hygiene". }\end{array}$} \\
\hline 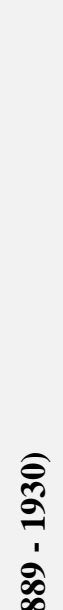 & $\begin{array}{l}\text { Reforma } \\
\text { Benjamin } \\
\text { Constant } \\
\text { 1890. }\end{array}$ & & & \\
\hline 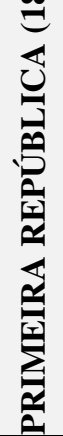 & $\begin{array}{l}\text { Reforma } \\
\text { Epitácio } \\
\text { Pessoa } 1901 .\end{array}$ & $\begin{array}{l}\text { Indicou a necessidade de } \\
\text { padronização, não respeitando a } \\
\text { identidades das IES ou as } \\
\text { particularidades regionais. } \\
\text { Demonstrou o caráter centralizador, } \\
\text { no que diz respeito as decisões } \\
\text { relacionadas ao processo } \\
\text { educacional, admitindo a } \\
\text { fiscalização, pelo Governo Federal, } \\
\text { nos estabelecimentos de ensino } \\
\text { particulares e estaduais, para sua } \\
\text { criação e funcionamentos }\end{array}$ & $\begin{array}{l}\text { Lei } \mathrm{n}^{\circ} 746 \text { de } 29 \text { de dezembro } \\
\text { de } 1900 . \\
\text { Decreto } \text { n }^{\circ} 3890 \text {, de } 1 \text { de janeiro } \\
\text { de } 1901 .\end{array}$ & $\begin{array}{l}\text { O Art. } 3^{\circ} \text {, da Lei } n^{\circ} 746 \text { de } 29 \text { de dezembro de } 1900 \text {, já descrevia a necessidade de se } \\
\text { prever disposições comuns para todos os "estabelecimentos de ensino superior". Desde } \\
\text { então, observava-se a necessidade de padronização, não respeitando a identidade das } \\
\text { IES ou as particularidades regionais. } \\
\text { O Decreto n' } 3890 \text {, de } 1 \text { de janeiro de 1901, em seu Art. } 1^{\circ} \text {, determinava que: As } \\
\text { Faculdades de Direito, as de Medicina, a Escola Politécnica, a de Minas e o Ginásio } \\
\text { Nacional fossem regidos pelo "Código dos Institutos Officiaes" e pelos "Regulamentos } \\
\text { Especiaes" que foram expedidos por força da Lei no } 746 \text { de } 29 \text { de dezembro de 1900, } \\
\text { Art. } 3^{\circ} \text {, revelando, indicativos de regulação da Educação Superior no Brasil. }\end{array}$ \\
\hline
\end{tabular}


Quadro 1 - Reformas Educacionais - Indícios Históricos - correlacionados com os processos de avaliação e regulação vigentes no Brasil

\begin{tabular}{|c|c|c|c|c|}
\hline \multicolumn{2}{|c|}{ Reformas Educacionais } & $\begin{array}{l}\text { Considerações relevantes para } \\
\text { o estudo, a partir das } \\
\text { Reformas } \\
\text { estudadas }\end{array}$ & \begin{tabular}{l}
\multicolumn{2}{l}{ Documentos estudados, } \\
em função das \\
Reformas \\
Educacionais
\end{tabular} & $\begin{array}{l}\text { Indícios históricos correlacionados com os processos de avaliação e } \\
\text { regulação vigentes no Brasil }\end{array}$ \\
\hline 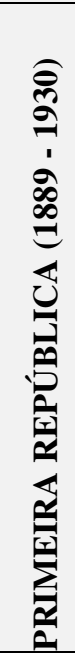 & $\begin{array}{l}\text { Reforma } \\
\text { Rivadávia } \\
\text { Correa - } 1911 .\end{array}$ & $\begin{array}{l}\text { Levou o liberalismo político às } \\
\text { últimas consequências, dentro do } \\
\text { positivismo ortodoxo, resolveu } \\
\text { retirar do Estado a interferência no } \\
\text { setor educacional, estabelecendo o } \\
\text { ensino livre. }\end{array}$ & $\begin{array}{l}\text { Decreto } \mathrm{n}^{\circ} 8659 \text {, de } 5 \text { de abril } \\
\text { de } 1911 .\end{array}$ & $\begin{array}{l}\text { O Decreto } \mathrm{n}^{\circ} 8659 \text {, de } 1911 \text {, ficou conhecido como Lei Orgânica do Ensino Superior e } \\
\text { Fundamental, elaborada pelo Ministro do Interior, Rivadávia da Cunha Corrêa. O } \\
\text { referido decreto trazia em seu Art. } 2^{\circ} \text { "Os institutos, até agora subordinados ao } \\
\text { Ministerio do Interior, serão, de ora em diante, considerados corporações autonomas, } \\
\text { tanto do ponto de vista didactico, como do administrativo" Assim, a Reforma } \\
\text { Rivadávia Corrêa ficou conhecida como a reforma que desoficializou o ensino } \\
\text { Brasileiro. } \\
\text { É interessante observar que, desde então, a Educação Superior Brasileira sofre com as } \\
\text { alterações bruscas em sua legislação. Porquanto a Reforma Epitácio Pessoa, admitia } \\
\text { a fiscalização, pelo Governo Federal, nos estabelecimentos de ensino particulares e } \\
\text { estaduais, para sua criação e funcionamento, na sequência, a Reforma Rivadávia } \\
\text { Corrêa, desoficializa. Mostra a história que a desoficialização gerada pela Reforma } \\
\text { Rivadávia favoreceu a abertura de escolas de variados perfis. Surgiram escolas } \\
\text { comprometidas em ofertar uma educação de qualidade, mas, sob a influência de um } \\
\text { mercado favorável, apareceram também, escolas que não eram assim tão } \\
\text { comprometidas ou sérias. Atualmente, existem processos que oficializam a educação, } \\
\text { mas ainda se percebe a falta de compromisso com a qualidade. O que leva ao } \\
\text { entendimento, de que por alguma razão, tais processos estão deixando a desejar. }\end{array}$ \\
\hline
\end{tabular}

(Continuação) 
Quadro 1 - Reformas Educacionais - Indícios Históricos - correlacionados com os processos de avaliação e regulação vigentes no Brasil

\begin{tabular}{|c|c|c|c|c|}
\hline \multicolumn{2}{|c|}{ Reformas Educacionais } & $\begin{array}{l}\text { Considerações relevantes para } \\
\text { o estudo, a partir das } \\
\text { Reformas } \\
\text { estudadas }\end{array}$ & $\begin{array}{l}\text { Documentos estudados, } \\
\text { em função das } \\
\text { Reformas } \\
\text { Educacionais }\end{array}$ & $\begin{array}{l}\text { Indícios históricos correlacionados com os processos de avaliação e } \\
\text { regulação vigentes no Brasil }\end{array}$ \\
\hline 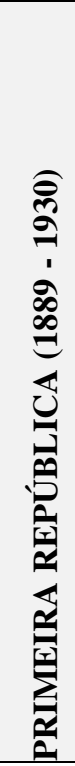 & $\begin{array}{l}\text { Reforma Carlos } \\
\text { Maximiliano - } \\
\text { 1915. }\end{array}$ & $\begin{array}{l}\text { Procurou conservar das reformas } \\
\text { anteriores o que nelas havia de } \\
\text { progressivo. } \\
\text { Preocupou com a oficialização do } \\
\text { ensino, enfatizando a } \\
\text { necessidade de melhorar a } \\
\text { qualidade, muito afetada pela } \\
\text { desastrosa e inoportuna reforma } \\
\text { conduzida por Rivadávia } \\
\text { Corrêa. }\end{array}$ & $\begin{array}{l}\text { Decreto } \mathrm{n}^{\circ} 11.530, \text { de } 18 \\
\text { de março de } 1915 \text {. }\end{array}$ & $\begin{array}{l}\text { O Decreto } \mathrm{n}^{\circ} 11.530 \text {, de } 18 \text { de março de } 1915 \text {, assinado pelo então presidente } \\
\text { Wenceslau Braz e por Carlos Maximiliano, ministro da Justiça e Negócios } \\
\text { Interiores, reorganizou o ensino secundário e superior na República. O } \\
\text { referido Decreto trazia entre suas determinações aspectos representativos da } \\
\text { fiscalização do ensino ofertado, ilustrando este fato, cita-se o seu Art. } 28 \text { " "O } \\
\text { Conselho Superior do Ensino será o órgão consultivo do Governo e o seu } \\
\text { auxiliar immediato para a fiscalização dos institutos officiaes e dos } \\
\text { equiparados a estes." O Decreto } \mathrm{n}^{\circ} 11.530 \text {, de } 18 \text { de março de } 1915 \text {, ainda } \\
\text { trazia em seu texto, disposições especiais, que tratavam dentre outros, de } \\
\text { aspectos específicos relacionados às Faculdades de Direito, de Medicina, ao } \\
\text { curso de Engenharia Civil, de Engenharia Mecânica e de Eletricidade, } \\
\text { detalhando inclusive, as cadeiras que seriam ministradas em cada um dos } \\
\text { cursos considerados. Nota-se que o Decreto no } 11.530 \text {, de } 18 \text { de março de } \\
\text { 1915, trouxe de volta o caráter oficial do ensino, considerando aspectos tanto } \\
\text { gerais como específicos, deixando evidenciado o caráter fiscalizador. Em } \\
\text { momento algum foram tratados ou considerados aspectos relacionados à } \\
\text { qualidade da educação ofertada ou a preocupação em avaliar os serviços } \\
\text { prestados, muito pelo contrário previa-se punição, caso as determinações } \\
\text { previstas não fossem atendidas. }\end{array}$ \\
\hline
\end{tabular}

Fonte: Elaborado pela autora (2016). 
Ao estudar a Primeira República, em especial as reformas educacionais, é possível verificar características presentes no modelo atual de Educação Superior Brasileiro. Um modelo essencialmente privado, baseado em faculdades isoladas, voltadas ao ensino, com pouca ou nenhuma ênfase na pesquisa ou na extensão. E que carrega em si, a preocupação com a expansão quantitativa, sem, necessariamente, apresentar garantias de qualidade. Além de um modelo de inspeção muito semelhante ao de avaliação que se tem hoje em dia, ou seja, passados 125 anos, continuam sendo adotadas as mesmas práticas de inspeção.

Ao se correlacionar as informações históricas organizadas no Quadro 1, com a atual realizada da Educação Superior Brasileira, nota-se características ainda presentes, a saber:

a) Alargamento dos canais de acesso, sem a necessária preocupação com a qualidade;

b) Aprovação prévia dos "programas de ensino", sem o estabelecimento de parâmetros prédefinidos, relacionados com as necessidades do mercado de trabalho;

c) Criação de "regulamentos para a inspeção" de estabelecimentos de ensino, atualmente estão materializados nos instrumentos de avaliação, favorecendo a realização de processos avaliativos pontuais e fragmentados;

d) Necessidade de se estabelecer disposições comuns para todos os "estabelecimentos de ensino superior", ou seja a busca pela padronização, não respeitando a identidade das IES ou as particularidades regionais.

Chama atenção, o fato de ainda se estar as voltas com tais questões, apesar do tempo, da história construída e das experiências vividas nessa área. Já era tempo de se perceber um modelo de avaliação que favorecesse a construção de uma cultura educacional voltada para a qualidade. Uma avaliação que fosse capaz de produzir sentido, que pudesse ser percebida como uma prática social. E que, verdadeiramente, contribuísse para a melhoria constante da qualidade, que orientasse a expansão da oferta. E, ainda, que propiciasse o aumento permanente da eficácia institucional e efetividade acadêmica e social, que promovesse o aprofundamento dos compromissos e responsabilidades sociais das IES, por meio da valorização da sua missão, da promoção dos valores democráticos, do respeito à diferença e à diversidade, da afirmação da autonomia e da identidade institucional. 


\section{A Era Vargas (1930 - 1945) e o estatuto das universidades (1931)}

Um dos primeiros atos do governo do presidente Getúlio Vargas, em 1930, foi a criação do Ministério da Educação e Saúde, que tinha a sua frente Francisco Campos. Foi este homem que deu nome em 1931, a Reforma que organizou de forma efetiva o ensino secundário e superior no Brasil. Ao considerar este período histórico e correlacioná-lo com o objeto de estudo desta pesquisa, surgiu a necessidade de examinar em especial o Estatuto das Universidades. O que levou a demonstração de que o modelo regulatório adotado, atualmente, carrega em si fortes características deste passado.

O Estatuto das Universidades pode ser considerado um marco estrutural de regulação da Educação Superior no Brasil, foi instituído na gestão do então Ministro da Educação e da Saúde Pública Francisco Campos, por meio do Decreto nº 19.851, de 11 de abril de 1931. Nessa data, foram publicados mais dois decretos: o ${ }^{\circ}$ 19.850, que criou o Conselho Nacional de Educação e o $\mathrm{n}^{\circ}$ 19.852, que dispôs sobre a organização da Universidade do Rio de Janeiro. Sobre tais documentos, Rothen (2006, p. 135), comenta:

[...] não há uma concepção homogênea de universidade, e de educação superior, sendo o Estatuto das universidades brasileiras, apesar das suas ambiguidades - e, quem sabe por causa delas -, representativo das concepções que permearam a discussão posterior sobre o modelo de universidade a ser, então, adotado no Brasil.

Ao observar os três Decretos citados, notam-se que são relevantes, mas, não, necessariamente, pelo que eles propunham, mas, sim, por explicitar dilemas da universidade brasileira. Rothen (2006, p. 136), aponta que tais dilemas continuam presentes até hoje, sendo eles:

Autonomia universitária deve ser plena ou restringida pelo Estado? Qual o grau de autonomia desejável?

Qual deve ser a prioridade do ensino realizado na universidade? A formação profissional? A formação cultural? As duas?

Qual a flexibilidade desejável para os cursos de graduação?

É aceitável o ensino superior fora do sistema universitário?

Qual o melhor método de ensino? É aceitável o uso intensivo de aulas expositivas? Em que dimensão devem ser inseridas as atividades práticas?

Como a universidade pode contribuir para a sociedade? Qual o seu papel no desenvolvimento brasileiro?

Qual estrutura organizacional permitiria à universidade não se resumir a uma federação de faculdades isoladas?

Como garantir a indissociabilidade entre o ensino, pesquisa e extensão?

As respostas para tais dilemas são complexas, mas não deixam de estar nas entrelinhas do modelo de avaliação da Educação Superior adotado e dos dados que são apresentados na seção III 
deste estudo. A autonomia universitária é restringida pelo Estado, a prioridade do ensino universitário tem sido a formação profissional e este fato é histórico. A flexibilidade desejável é aquela que não impede o lucro das IES privadas que é maioria. E sim, é aceitável que o "ensino superior" ocorra fora do sistema universitário, pois este é composto essencialmente por faculdades. O método de ensino, a proporção entre aulas expositivas ou práticas não necessariamente são motivos de preocupação.

\section{A universidade no Brasil (1946-1963)}

Com o fim do Estado Novo ${ }^{1}$, após a deposição de Getúlio Vargas do cargo de presidente, Eurico Gaspar Dutra foi eleito, em 2 de dezembro de 1945, assumindo a presidência da república em 31 de janeiro de 1946. Também em 1946 foi promulgada a nova Constituição, que no contexto educacional evidenciou a norma de que a educação era direito de todos e que poderia ser ministrada também pela iniciativa privada, desde que respeitadas as leis vigentes, Brasil (1946, p. 55):

Art 166 - A educação é direito de todos e será dada no lar e na escola. Deve inspirar-se nos princípios de liberdade e nos ideais de solidariedade humana.

Art 167 - O ensino dos diferentes ramos será ministrado pelos Poderes Públicos e é livre à iniciativa particular, respeitadas as leis que o regulem.

É importante ressaltar que, a Constituição de 1946, também, contribuiu no âmbito educacional, ao favorecer o processo de discussão do que se configurou como sendo a primeira Lei de Diretrizes e Bases (LDB) que foi aprovada em 1961. A LDB definiu e regularizou o sistema educacional Brasileiro com base nos princípios presentes na Constituição. E neste contexto, vale refletir sobre as concepções, os papéis e as funções que envolvem a universidade brasileira. E, Boaventura S. Santos (1997, p. 17), questiona; “Que é hoje a Universidade? Um supermercado de disciplinas? Um santuário de erudição? Uma agência de capacitação de profissionais? Uma instituição crítica?"

Acredita-se que, atualmente, a universidade brasileira carrega um pouco de cada uma das características consideradas por Boaventura S. Santos em seus questionamentos. É supermercado, enquanto mecanismo que atende as demandas da sociedade de massa. É santuário, ao atender a

\footnotetext{
${ }^{1}$ O Estado Novo foi a denominação que se deu ao período em que Getúlio Vargas governou o Brasil de 1937 a 1945. Este período ficou marcado, no campo político, por um governo ditatorial.
} 
elite. É também agência de capacitação profissional, por estar inserida em uma sociedade que percebe na Educação Superior, uma forma de ascensão social e econômica. Igualmente, não deixa de ser uma instituição crítica, pois atua na produção de conhecimento e precisa preservar valores acadêmicos, que são fundamentais, como a liberdade e pluralidade de ideias.

Boaventura S. Santos (1997, p. 17), comenta: “A variedade de concepções acerca da organização acadêmica reflete as fortes pressões para que ela venha a exercer outras funções além das habituais de ensino, pesquisa e extensão". Levando ao entendimento que cada vez mais a universidade precisa ir além, para corresponder mais diretamente aos anseios da sociedade por um país democrático, cujos cidadãos participem ativamente na definição dos projetos de seu desenvolvimento. Ao correlacionar esta reflexão, com os processos de avaliação externa de cursos de graduação, evidencia-se que, independentemente, do que venha a ser a universidade brasileira e das funções que venha a exercer, precisa-se de uma avaliação flexível, dinâmica, que respeite as diferenças.

\title{
6 A Reforma Universitária de 1968
}

Como consequência da Reforma de 1968, um novo padrão de Educação Superior se instalou no Brasil, privilegiando uma estrutura seletiva, tanto acadêmica como social. A crescente demanda por acesso a educação era atendida pela iniciativa privada, que se organizou por meio de empresas educacionais. Conforme aponta Gomes (2016, p. 24):

\begin{abstract}
A Reforma Universitária de 1968 [...] teve como objetivo a racionalização e modernização da Educação Superior, visando a atender as demandas de uma economia que rapidamente se diversificava e ampliava o setor de serviços. O Estado investiu em infraestrutura e na indústria de base, e as burocracias pública e privada expandiram-se notavelmente, o que ampliou a demanda por Educação Superior, sobretudo porque as classes médias percebiam a aquisição do diploma universitário como um dos mais importantes veículos para ascender social e economicamente.
\end{abstract}

Fato ainda verificado nos dias atuais, afinal em nossa sociedade a obtenção do diploma universitário é entendida como algo capaz de favorecer a ascensão econômica e social.

Muitas das transformações na organização das universidades brasileiras se deram por meio da Lei $n^{\circ}$ 5540, de 28 de novembro de 1968, que fixou normas de organização e funcionamento da educação, destacando, Brasil (1968, p. 1):

Art. $1^{\circ}$. O ensino superior tem por objetivo a pesquisa, o desenvolvimento das ciências, letras e artes e a formação de profissionais de nível universitário. 
Art. $2^{\circ}$. O ensino superior, indissociável da pesquisa, será ministrado em universidades e, excepcionalmente, em estabelecimentos isolados, organizados como instituições de direito público ou privado.

Art. $3^{\circ}$. As universidades gozarão de autonomia didático-científica, disciplinar, administrativa e financeira, que será exercida na forma da lei e dos seus estatutos.

$[\ldots]$

Art. $5^{\circ}$. A organização e o funcionamento das universidades serão disciplinados em estatutos e em regimentos das unidades que as constituem, os quais serão submetidos à aprovação do Conselho de Educação competente.

Assim, entende-se que a Reforma de 1968 alterou o modelo de funcionamento das universidades brasileiras, que aos poucos incorporaram as modificações acadêmicas indicadas pela Reforma, provocando efeitos paradoxais, pois, se por um lado a Reforma de 1968 promoveu inovações, por outro, favoreceu o surgimento de instituições organizadas a partir de estabelecimentos isolados, voltados para a transmissão de conhecimentos de caráter profissionalizante sem nenhum vínculo com atividades de pesquisa, ou com a formação intelectual e crítica da sociedade Brasileira. Paradoxos tão presentes atualmente na rotina da Educação Superior ofertada no Brasil, apesar de ser avaliada periodicamente.

Vale ressaltar aqui, que este estudo em momento algum enfatiza a não realização dos processos avaliativos. Muito pelo contrário, defende-se que tais processos sejam realizados periodicamente, o que se coloca em debate é o modelo sob o qual estes processos estão sendo realizados.

A expansão, ou seja, a democratização do acesso à Educação Superior, adquiriu força nos últimos anos, e representa um aspecto discutido por vários autores, como por exemplo Fávero (2006, p. 73-74), que afirmou:

Devo dizer, antes de mais nada, que falo em nome de uma filosofia de expansão universitária consubstanciada nos seguintes postulados:

a) a expansão constitui um processo ambíguo, que tanto poderá dilatar nossas mediocridades quanto provocar a ruptura do status quo, com a introdução de novos marcos qualitativos;

b) só na segunda hipótese a expansão representa um meio de desenvolvimento, pela substituição de um equilíbrio social pelo outro;

c) a expansão constitui um fator de democratização, segundo a clientela a que vai beneficiar, a mudança de papéis que ensejará a seus destinatários - papéis na acepção esposada por sociólogos e antropólogos como Nadel, enfim, segundo a elevação de padrões de vida da comunidade, através dos serviços a serem desempenhados pelos novos quadros profissionais; [...].

Entende-se que a expansão do acesso à Educação Superior é válida, desde que acompanhada de garantias de qualidade. De acordo com Cunha (1986) a concentração de renda, fato marcante na 
sociedade Brasileira, levou as classes médias a perceber na Educação Superior um meio para ascensão social, entendendo a educação como forma de melhorar a renda familiar e assim ascender socialmente.

Atualmente, ainda se percebe a influência da Reforma de 1968 na Educação Superior Brasileira, ofertada em sua maioria pela iniciativa privada carrega em si características desse passado. Mas a educação deve ser capaz de cumprir sua função social e a partir da realidade na qual acontece promover mudanças, para tanto defende-se que a avaliação externa de cursos de graduação tem um papel primordial.

\section{Avaliação da educação superior nos anos de 1980 - PARU (1983-1984)}

Mas no que diz respeito à avaliação dos cursos de graduação, há de se admitir que até os anos de 1970 não se percebia alterações significativas. Pode-se afirmar, que foi nas últimas décadas, que discussões e ações relativas a esta avaliação ganharam força. Apenas na década de 1980, surgem as primeiras propostas, por meio do Programa de Avaliação da Reforma Universitária (PARU).

As primeiras iniciativas de avaliação dos cursos de graduação surgiram na década de 1980, com o Programa de Avaliação da Reforma Universitária (PARU), apresentado pelo Ministério da Educação em função das greves nas Universidades Públicas e da preocupação com a qualidade da Educação Superior oferecida.

O PARU utilizava como metodologia a aplicação de questionários aos docentes, aos dirigentes universitários e aos estudantes. Visava coletar informações inerentes à organização didática e administrativa das IES, à expansão de ingressos e à avaliação das atividades de ensino, pesquisa e extensão. Nesse sentido vale salientar que, a diversidade de instituições e informações envolvidas nos processos avaliativos ainda se configura como um desafio a ser superado pelo modelo de avaliação adotado.

\section{Programa de Avaliação Institucional das Universidades Brasileiras - PAIUB (1993-1994)}

O Programa de Avaliação Institucional das Universidades Brasileiras (PAIUB) foi estabelecido pelo MEC, em 1993 e propiciou o surgimento das primeiras iniciativas de autoavaliação, para auxiliar no processo de aperfeiçoamento da instituição. 
Visava a construção de um processo de avaliação contínuo, capaz de promover o aperfeiçoamento do desempenho acadêmico e de prestação de contas da Universidade à sociedade. Constituiu-se em um instrumento para o planejamento da gestão e do desenvolvimento da Educação Superior. Dessa forma, o Paiub estabeleceu três fases centrais para o processo a ser desenvolvido em cada universidade: Avaliação Interna, Avaliação Externa e Reavaliação.

Este programa estabeleceu uma nova forma de relacionamento com o conhecimento e com a formação e fixou um diálogo com a comunidade acadêmica e com a sociedade. Embora sua experiência tenha sido curta, conseguiu dar legitimidade à cultura da avaliação e promover mudanças visíveis na dinâmica universitária. Esse processo resgatou a legitimidade da avaliação, uma vez que o amplo debate, então estabelecido com a comunidade universitária, estimulou a adesão voluntária das instituições ao processo avaliativo, assim, considera-se o Paiub uma boa referência no processo de avaliação da Educação Superior.

\section{Avaliação da educação superior no Brasil - 1995/2003, do PAIUB ao Exame Nacional de Cursos}

O fato histórico aqui considerado para marcar o ano de 1995, foi o primeiro mandato do então presidente Fernando Henrique Cardoso. Governo que se empenhou em regulamentar a nova LDB, Lei nº 9.394, de 1996 (BRASIL, 1996), em vigor até os dias atuais.

Ao correlacionar o período histórico, compreendido entre os anos de 1995 e 2002, com os processos de avaliação da Educação Superior, enfatiza-se a desaceleração do Paiub e o surgimento dos Exames Nacionais de Cursos, obrigatórios para todos os estudantes do último ano dos cursos superiores de graduação do País. Considera-se tal fato como um retrocesso no avanço dos processos de avaliações de cursos no Brasil. O então, Provão, foi muito criticado na época, por ser um exame único e comum para todos os cursos no Brasil. Levou ao entendimento que este poderia impor um currículo padronizado, aniquilando, assim, possibilidades para se diversificar o sistema de Educação Superior, não respeitando a diversidade cultural, geográfica e demográfica do País.

Com o fim do Provão, a partir de 2004, o Enade passou a cumprir este papel. Objetivou avaliar o desempenho dos estudantes com relação aos conteúdos programáticos previstos nas diretrizes curriculares dos cursos de graduação. Todavia, o Enade carrega em si características que favorecem críticas antes aplicadas ao Provão, como por exemplo, a falta de articulação dos seus 
componentes, a elaboração de rankings. Dessa forma, conforme as características do Paiub que perdia força e do Provão que surgia com muita força, confirma-se o retrocesso no processo avaliativo, aqui estudado.

\section{Avaliação da Educação Superior no Brasil, de 2003 aos dias atuais}

Ao estudar os processos de avaliação da Educação Superior no Brasil, no período compreendido entre os anos de 2003 e 2010, é impossível não considerar os dois governos de Luiz Inácio Lula da Silva (2003/2006 e 2007/2010). Neste período, de 2003 a 2010, o Brasil teve três Ministros da Educação, a saber: Cristovam Buarque, Tarso Genro e Fernando Haddad. Contudo, foi na gestão do Ministro Fernando Haddad que foram criados índices, conceitos e insumos educacionais, baseados em exames de larga escala, utilizados até os dias de hoje.

Em dezembro de 2003, foi editada a Medida Provisória 147/2003, que instituiu o Sinapes. Porém, em 2004 ocorreu a reforma ministerial e Cristovam Buarque foi substituído por Tarso Genro. Momento em que foi votado pelo Congresso Nacional, o projeto de Conversão da Medida Provisória 147/2003 em Lei. Assim, foi promulgada como a Lei nº 10.861, em 14 de abril de 2004, instituindo o Sinaes, que se encontra em vigor até os dias atuais. O Sinaes considerou, parcialmente, os princípios emancipatórios da primeira proposta e conciliou tais princípios com a concepção regulatória, atribuída a avaliação, combinou-a com regulação, fato que até hoje gera polêmica.

Com a institucionalização do Sinaes, a Comissão Nacional de Avaliação da Educação Superior $\left(\right.$ CONAES $^{2}$ ), instituída pela Portaria n ${ }^{\circ} 2051$, de 9 de julho de 2004, produziu documentos e diretrizes, visando atender a avaliação externa, a autoavaliação e a avaliação de cursos. Inicialmente, a Conaes divulgou as Diretrizes para a Avaliação das IES e o roteiro de autoavaliação institucional. Assim, teve início a concepção de ciclo avaliativo, utilizada até os dias atuais. Neste levantamento histórico, merece destaque o ano de 2017. Ano em que foram publicados os novos instrumentos de avaliação, vigentes atualmente, bem como um conjunto de portarias que passaram a subsidiar os processos avaliativos aqui estudados e portanto foram considerados em todas as análises realizadas.

${ }^{2}$ CONAES é o órgão colegiado de coordenação e supervisão do SINAES, instituído pela Lei no 10.861 , de 14 de abril de 2004.

Avaliação, Campinas; Sorocaba, SP, v. 25, n. 2, p. 238-256, jul. 2020 
Os procedimentos de avaliação aqui considerados estão em vigor até os dias atuais, motivo pelo qual a análise histórica será concluída aqui, não se estenderá para o governo que se instaurou após o segundo mandato do Presidente Lula.

\section{Considerações finais}

As práticas de avaliações da Educação Superior, que visam mensurar a qualidade, influenciando nos modelos de funcionamento das Instituições de Ensino Superior (IES) e de seus cursos, têm assumido lugar de destaque nas pautas educacionais. Os governantes atribuem a estas avaliações uma importante função na determinação das políticas públicas, pois as consideram mecanismos capazes de organizar as reformas necessárias para assegurar uma educação de qualidade.

Porém o presente estudo, revela que fragilidades se mantém ao logo do tempo, pois já no final da Primeira República (1889/1930), evidenciavam-se problemas, como a falta de estrutura universitária; revelam então a necessidade de se estabelecer políticas públicas capazes de melhor estruturar a Educação Superior no Brasil. Avalia-se tanto, nos dias atuais e, ainda assim, a realidade não mudou. Este já foi o cenário educacional que Getúlio Vargas encontrou ao assumir a Presidência da República, uma vez que este fora levado ao poder em 1930.

Entende-se, que a qualidade da educação é um fenômeno complexo, abrangente, que envolve muitas dimensões e, assim, sendo, deve ser avaliada de forma sistêmica e global, pois o sistema educacional é formado por múltiplos componentes que se inter-relacionam e se influenciam mutuamente. Acredita-se, que a qualidade educacional deve ser avaliada em seu conjunto, medidas isoladas não surtirão efeito.

Processos avaliativos, que objetivam medir a qualidade educacional, precisam se pautar em avaliações formativas, indo além do simples enquadramento de produtos. Avaliar e compreender os processos gerados, consistindo em uma ação sistemática que busca a compreensão global da educação, pelo reconhecimento e pela integração de suas diversas dimensões, desconsiderando práticas avaliativas pontuais e fragmentadas.

Entre estas muitas dimensões está, inclusive, a concepção do que se entende por educação. E para esclarecer a concepção de educação sob a qual está pautado este estudo, buscou-se Paulo 
Freire (2007) que defendia uma educação emancipadora como direito humano. Educação que exerce um papel social importante e se configura como, sendo um caminho para minimizar as diferenças sociais. Paulo Freire percebia a Educação como um processo humanizante, social, político, ético, histórico e cultural. Alicerçada sobre a base da ação reflexiva e dialógica que se articula como possibilidade de transformação da pessoa e da sociedade. Como aponta Freire (2007, p. 44): "Educação que, desvestida da roupagem alienada e alienante, seja uma força de mudança e de libertação".

Quanto ao conceito de qualidade, está atrelado as demandas e exigências sociais. Assim, a avaliação de que trata este estudo precisa ser flexível, dinâmica e diversificada. Dessa maneira terá condições de verificar se a educação ofertada em certo tempo e lugar é de qualidade, atendendo as demandas sociais e melhorando a vida das pessoas.

\section{Referências}

APPOLINÁRIO, F. Dicionário de metodologia científica: um guia para a produção do conhecimento científico. São Paulo: Atlas, 2009.

BARDIN, L. Análise de conteúdo. Lisboa, Portugal: Edições 70, 2009.

BRASIL. Lei de Diretrizes e Bases n. 9394/96. Brasília: MEC, 1996. Disponível em: http://www.planalto.gov.br/ccivil_03/leis/19394.htm. Acesso em: 11 mar. 2018.

BRASIL. Presidência da República. Constituição dos Estados Unidos do Brasil, de 18 de setembro de 1946. Disponível em: http://www.planalto.gov.br/ccivil 03/constituicao/constituicao46.htm. Acesso em: 10 mar. 2018.

BRASIL. Presidência da República. Lei no 5540, de 28 de novembro de 1968. Disponível em: http://www.planalto.gov.br/ccivil 03/leis/L5540.htm. Acesso em: 03 jun. 2018.

CHIZZOTTI, A. Pesquisa qualitativa em ciências humanas e sociais. Petrópolis: Vozes, 2006.

CUNHA, Luiz Antônio. A universidade temporã - da Colônia à Era Vargas. 2. ed. Rio de Janeiro: Livraria Francisco Alves, 1986.

FÁVERO, Maria de Lourdes de Albuquerque; BRITTO, Jader de Medeiros (orgs). Durmeval Trigueiro Mendes: ensaios sobre educação e universidade. Brasília: INEP, 2006. 
FONSECA, J. J. S. Metodologia da pesquisa científica. Fortaleza: UEC, 2002. Apostila.

FREIRE, Paulo. Educação como prática da liberdade. São Paulo: Paz e Terra, 2007.

GIL, A. C. Como elaborar projetos de pesquisa. 4. ed. São Paulo: Atlas, 2007.

GOMES, Alfredo Macedo. Expansão e privatização da educação superior: do período civilmilitar ao neoliberalismo-popular. In: SOUZA, José Vieira de; CUNHA, Célio da; SILVA, Maria Abádia da (org.). Expansão e avaliação da educação superior: cenários e vozes. Belo Horizonte: Fino Traço, 2016. p. 21-50.

MAY, T. Pesquisa social: questões, métodos e processo. Porto Alegre: Artmed, 2004.

OLIVEIRA, M. M. Como fazer pesquisa qualitativa. Petrópolis: Vozes, 2007.

ROTHEN, J. C. Ponto e contraponto na avaliação institucional: análise dos documentos de implantação do Sinaes. Revista Educação: Teoria e Prática, Belo Horizonte, v. 15. n. 27, p. 119137, 2006.

SÁNCHEZ, Silvio Gamboa. Pesquisa em educação: métodos e epistemologias. 2. ed. Chapecó: Argos, 2012.

SANTOS, Boaventura de Sousa. Pela mão de Alice. O social e político na pós-modernidade. 9. ed. São Paulo: Cortez, 1997.

TEIXEIRA, Anísio. O ensino superior no Brasil: análise e interpretação de sua evolução até 1969. Rio de Janeiro: Fundação Getúlio Vargas, 1969. 